Review Article

\title{
A Scrupulous Review on Multifaceted Pyrazole Nucleus as an Energetic Pharmacological Agent
}

\section{Amala Babu ${ }^{* 1}$, Sneha Antony ${ }^{1}$, Femy Maria KM ${ }^{1}$, Dr.Vinod B ${ }^{2}$}

${ }^{1}$ Student, Department of Pharmaceutical Chemistry, St. Joseph's College of Pharmacy, Dharmagiri Campus, Cherthala, Kerala, India. ${ }^{2} \mathrm{HOD}$ and Professor, Department of Pharmaceutical Chemistry, St. Joseph's College of Pharmacy, Dharmagiri Campus, Cherthala, Kerala, India.

*Corresponding author's E-mail: amalababu3110@gmail.com

Received: 14-05-2021; Revised: 26-07-2021; Accepted: 05-08-2021; Published on: 15-08-2021.

\section{ABSTRACT}

Pyrazole represents a versatile class among heterocyclic compounds due to its impact in biological and pharmacological field irrespective of its scarcity in nature. From the structural point of view, pyrazoles are rather interesting and chemically it is known as 1,2-Diazoles.Also, it is a five membered heterocyclic compound containing 2 Nitrogen atoms. As per different studies, Pyrazoles and its derivatives own a wide range of biological activities like Antibacterial, Analgesic, Antioxidant etc. The main intention of this review is to run an overview of diverse pharmacological activities of pyrazole moiety especially antimicrobial, anti-inflammatory, antioxidant, analgesic, Hypoglycemic, anticancer and enzyme inhibitory effects.

Keywords: Pyrazole, Chemistry, Synthesis, Biological activity.

QUICK RESPONSE CODE $\rightarrow$

DOI:

10.47583/ijpsrr.2021.v69i02.036

DOI link: http://dx.doi.org/10.47583/ijpsrr.2021.v69i02.036

\section{INTRODUCTION}

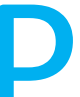

yrazole scaffolds symbolises a privileged structure in medicinal chemistry due to its diverse biological activities. The first natural pyrazole, 1-Pyrazolinyl alanine was isolated from seeds of watermelon in the year $1957^{1}$.Pyrazoles fit in closed chain, aromatic and heterocyclic type of compound containing 2 Nitrogen atoms as a part of ring system having molecular formula $\mathrm{C}_{3} \mathrm{H}_{3} \mathrm{~N}_{2} \mathrm{H}$. Hence, they called as Azoles.

Among the Heterocyclic compounds, nitrogen-containing heterocycles are extensively found as a key outline in a huge library of heterocycles and show several hires in natural science and other areas of science ${ }^{2}$. One of the most potential families of nitrogen containing compounds is Pyrazoles. During the last few years, numerous azole derivatives have been found to possess a comprehensive spectrum of pharmacological activities. Among the multitude of compounds in azole family, pyrazole derivatives show structural diversity and a wide range of applications in major fields, including in the pharmaceutical industry ${ }^{3-9}$. Pyrazoles belongs to five membered heterocycles are very sporadic in nature was ascribed to the presence of $-\mathrm{N}-\mathrm{N}$ - bond in their structure, a chemical motif assumed to be of very challenging formation by living organism ${ }^{10}$. Pyrazoles act as building blocks in synthesis of many heterocyclic system ${ }^{11}$. From the medicinal point of view, this class of compounds are biologically active and rendering them worthy of deeper investigations ${ }^{12-14}$. Pyrazoles display rich reactivity which is linked to their challenging structure that exhibit a possibility of tautomerism. And also, they offering versatility for application in synthetic organic chemistry due to the presence of a multifarious framework ${ }^{15-17}$.

In this manuscript, we will emphasis on pyrazole moiety addressing its structure, chemistry and synthesis with a special interest on its biological applications. Literature discloses that compounds having pyrazole nucleus have a wide spectrum of pharmacological activities such as antimicrobial, antioxidant, analgesic, anti-inflammatory, anticancer, Hypoglycaemic, enzyme inhibitory properties etc. Due to its varied range of biological activities, pyrazole ring contributes an appropriate synthetic route in pharmaceutical industry. In fact, this heterocyclic moiety represents core nucleus for a number of drugs.

\section{CHEMISTRY}

- In the past, chemistry of pyrazole has been extensively investigated. Pyrazoles, a five membered heterocycle containing 2 Nitrogen atoms; Pyrrole type and Pyridine type, in adjacent position and hence called as Azoles.

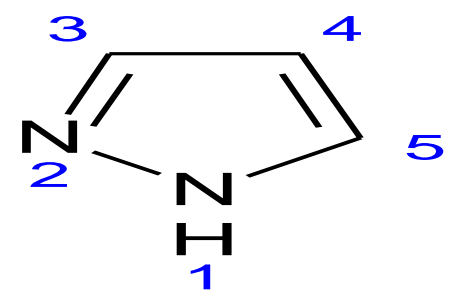

Figure 1 
- $\quad$ Pyrazoles exist in three partially reduced forms ${ }^{18}$. They are named as Pyrazolines; while completely reduced form is Pyrazolidine.<smiles>C1CN=NC1</smiles>

1-Pyrazoline<smiles>C1=NNCCN1</smiles>

2-Pyrazoline<smiles>C1CNNC1</smiles>

Pyrazolidine

Figure 2

- By the effect of individual atoms, the chemical reactivity of pyrazole can be explained.

- There are 2 Nitrogen atoms at position 1 and 2 . Among them, Pyridine type nitrogen atom at position 2 with a lone pair of electrons exhibit basic nature and is vulnerable for electrophilic attack. Nitrogen atom at position 1 remain unreactive but it can loose its $\mathrm{H}+$ ions in existence of a base. Because the $\mathrm{H}$-atom attached to Nitrogen at position 1 is more acidic than Pyrrolic N-H ${ }^{18}$.

- There is a reduction in charge density at C3 and C4 due to the combination of 2-Nitrogen atoms, making them vacant for electrophilic reagent attack.

- In presence of a strong base, deprotonation can occur at C3 and it may lead to ring opening.

- Due to the addition of $\mathrm{H}+$ ions to pyrazole, pyrazolium ions will form which are less likely to experience the electrophilic attack at C4 but promotes the electrophilic attack at C3.

- The reactivity towards electrophile is enhanced and anions of pyrazoles are much less reactive towards nucleophilic attack ${ }^{19}$.

- Pyrazoles unsubstituted in position 1 shows $\mathrm{N}-\mathrm{H}$ acidity. Therefore, the Pka value of pyrazole is 14.1 and it is equal to that of imidazole.

- Pyrazoles deliberated as a flexible lead compound which are aromatic due to their planar conjugated ring structure with 6 delocalized $\pi$ e-s. Consequently, many of the significant properties of these molecules have been anticipated by matching with the properties of benzene analogues ${ }^{20}$.

- Tautomerism is a key feature that stalks from the aforementioned ability of pyrazoles to exchange protons. Like other nitrogen containing heterocyclic compounds, pyrazoles also possess different tautomeric forms. Three tautomeric structures for unsustituted pyrazoles can be illustrated ${ }^{21}$. Here there is a swift migration of hydrogen from one nitrogen to the other.

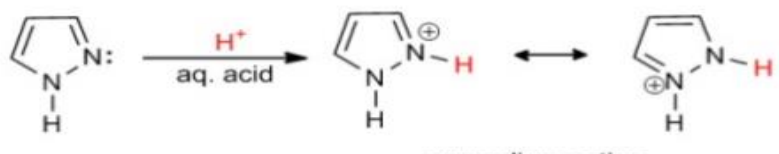

pyrazolium cation

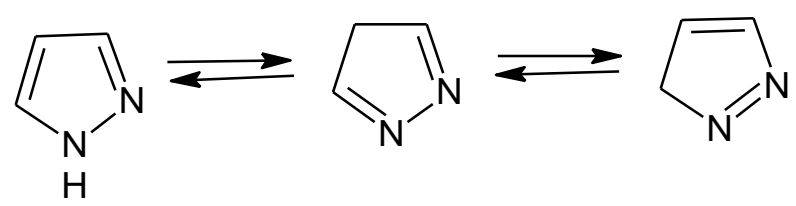

Figure 3: Tautomeric forms of unsubstituted pyrazoles CHEMICAL REACTIVITY OF PYRAZOLE

Pyrazoles undergoes the following type of chemical reactions.

\section{1) Reaction with electrophilic reagent}

Generally, pyrazoles exhibit electrophilic addition to Nitrogen and electrophilic substitution to carbon

\section{a) Electrophilic addition to nitrogen}

It involves Protonation and $\mathrm{N}$-alkylation/ $\mathrm{N}$-arylation

- Protonation occurs in $\mathrm{N}$-atom at position 2 via pyridine type nitrogen atom. Therefore, it reacts with electrophiles.

- 3,5-disustituted pyrazoles undergo $\mathrm{N}$-arylation with 4-fluronitrobenzene and 2-fluronitrobenzene using potassium terbutoxide in DMSO using different methods. This method results in $\alpha$-regioisomers in excellent yields ${ }^{22}$.

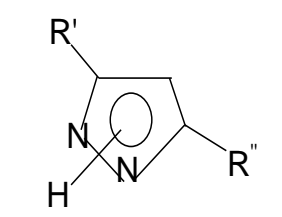

3,5-Disustituted pyrazole

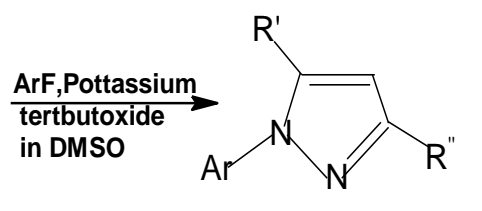

$\mathrm{N}$-aryl substituted pyrazole

\section{$\mathrm{ArF}=4-$ Fluoronitrobenzene} 2-Fluoronitrobenzene

\section{Figure 4}

\section{b) Electrophilic substitution to carbon}

- Electrophilic substitution on carbon of pyrazoles facilitates more

- slowly than for pyrroles and at about the same rate as for benzene.

- At C3 and C5, the electrophilic attack generates highly unstable positively charged Azomethine intermediate.

- At C4, complete electrophilic attack occurs without any generation of such highly unstable intermediate. 
- The reactions such as nitration and halogenation are the important electrophilic substitution reactions that occurs at carbon atom of pyrazole.

- Direct nitration of a variety of pyrazoles with nitric acid/trifluoroacetic anhydride affords mononitroderivative in an average yield of $60 \%$.

- 3,5-dimethyl pyrazole undergo reaction with nitrating system $\left[\mathrm{HNO}_{3} \&\left(\mathrm{CF}_{3} \mathrm{CO}\right)_{2} \mathrm{O}\right]$ gives only 3,5dimethyl-4-nitro pyrazole in $76 \%$ yield $^{23}$.<smiles>Cc1cc(C)[nH]n1</smiles>

3,5-Dimethylpyrazole

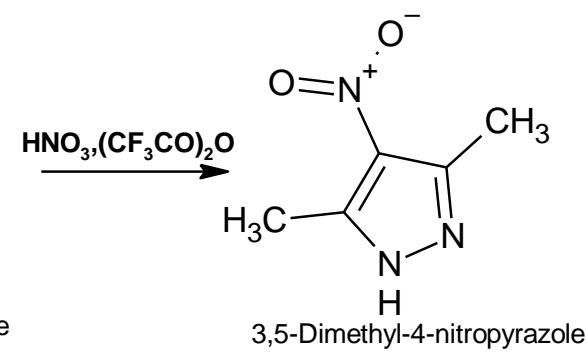

\section{2) Reaction with nucleophilic reagent}

Pyrazoles usually do not react with nucleophiles but if it react with them, the reaction will be very slow ${ }^{24}$. For instance, at position 3 of pyrazoles which is unsubstituited shows ring opening on heating with alkali hydroxides. In case of Halopyrazoles, the nucleophilic substitution of halogen is also difficult.

\section{Synthetic methods and Biological activities of Pyrazole}

Generally, pyrazoles are synthesized by (i) the reaction of 1,3-diketones with hydrazines, (ii) 1,3-dipolar cycloaddition of diazo compounds with alkynes and (iii) the reaction of $\alpha, \beta$-unsaturated aldehydes and ketones with hydrazines.

Mohyeddin Assali et al reported a facile synthetic approach in order to produce diaryl based pyrazoles which will act as selective COX-2 inhibitors. Pyrazole derivatives were synthesized by Vilsmeier-Haack reaction(Scheme 1).

Figure 5

\section{Scheme 1}<smiles>[R]c1ccc(NNN=C(C)c2ccc([R])cc2C(C)(C)C(C)C)cc1</smiles>

The newly synthesized compounds were tested for inhibition assay on COX-1 and COX-2 enzyme using COX-1 (Human) inhibitor screening assay kit and COX-2 (Human) inhibitor assay kit. In order to determine the maximal inhibitory concentration $\left(I C_{50}\right)$ and compare it with the $I C_{50}$ of celecoxib, serial concentration in the range (100 $\mu \mathrm{m}$ $0.001 \mu \mathrm{m}$ ) were used for each compound in the assay kit.

The invitro inhibition assay results showed that out of seven derivatives synthesized(4a-g), 4-(-formyl -3-phenyl-1Hpyrazol-1-yl)benzene -1-sulfonamide(4a) and 4-\{4-formyl3-[4-(methane sulfonyl)phenyl]-1H-pyrazol-1-yl\}benzene1-sulfonamide(4b) showed good and potent COX-2 selective inhibitory activity with $\mathrm{IC}_{50}$ of 0.017 and $0.098 \mu \mathrm{m}$ respectively.<smiles>NS(=O)(=O)c1ccc(-n2cc(C=O)c(-c3ccccc3)n2)cc1</smiles>

4-(4-formyl-3-phenyl-1H-pyrazol-1-yl)benzene-1-sulfonamide (4a)<smiles>CS(=O)(=O)c1ccc(-c2nn(-c3ccc(S(N)(=O)=O)cc3)cc2C=O)cc1</smiles>

4-\{4-formyl-3-[4-(methanesulfonyl)phenyl]-1H-pyrazol-1-y|\}benzene-1-sulfonamide(4b)

Figure 6 
The better inhibitory activity of compound $\mathbf{4 a}$ is due to the presence of a sulfonamide substituent on the $\mathrm{N}$-aromatic ring and other aromatic ring which was unsubstituted. However, the compound $\mathbf{4 b}$ with sulfonamide substituent on $\mathrm{N}$-aromatic ring and other aromatic ring was substituted with sulfone displayed better COX-2 selectivity and inhibitory activity ${ }^{25}$.

Kariyappa et al reported a simple easy accessible procedure for the synthesis of novel fused pyrans and their in vitro antibacterial and antifungal activity.

The synthesis proceeds by the condensation of 2-hydroxy acetophenones(1) with substituted phenyl hydrazine hydrochloride in ethyl alcohol and catalytic amount of acetic acid . This reaction produced hydrazones (2a-e) as the first product. Hydrazones endangered to Vilsmeier-Haack reaction using $\mathrm{DMF}$ and $\mathrm{POCl}_{3}$. The mixture was stirred at $60-65^{\circ} \mathrm{C}$ for $6 \mathrm{hrs}$. In between, the completion of the reaction was determined by TLC. Separated solids called pyrazole-4carbaldehyde (3a-e) were filtered and thoroughly washed with water. Recrystallization of intermediate product were done using ethanol. A series of novel fused pyrazole (4a-e) were fruitfully synthesized by intramolecular cyclization of 3-(2-hydroxyphenyl)-1-aryl-1H-pyrazole-4carbaldehyde(3a-e) in good yield(Scheme 2).

\section{Scheme 2}<smiles>CC(=O)NNC(=O)NNC(C)=O</smiles>

The newly synthesized Pyranopyrazoles (4a-e) were screened for their in vitro antibacterial and antifungal activity by the broth dilution technique. Here, MIC of synthesized compounds against different bacterial and fungal strains were determined. The bacterial strains are E.coli, Pseudomonas aeruginosa(gram negative), Staphylococcus aureus, Streptococcus pyogenes(gram positive) and thereby the fungal strains are Cryptococcus neoformans, Aspergillus niger, Aspergillus flavus, Candida albicans respectively. The standard drugs that were used against the bacteria and fungal species are antibiotic Ciprofloxacin and Amphotericin-B.

Among the 5 synthesized derivatives of Pyranopyrazoles (4a-e), the 2-(4-Chlorophenyl)-4-ethoxy-[1]benzopyrano [4,3-c]pyrazole (4b) disclosed outstanding activity (MIC:15) against Staphylococcus aureus than standard drug Ciprofloxacin (MIC:25).Also this derivative $4 \mathrm{~b}$ revealed noble activity(MIC:25) against $E$. coli than Ciprofloxacin (MIC:50) while derivatives $\mathbf{4 c}$ and $\mathbf{4 d}$ displayed equipotent activity. It is due to the chlorosubstitution in compound $\mathbf{4 b}$ influenced these molecules to exhibit inhibition to a greater extent against the organisms under consideration. Almost all newly synthesized derivatives(4a-e) exerted a moderate to good in vitro antifungal activity against all the tested organisms. The compound $\mathbf{4 b}$ having chlorosubstitution showed incredible activity at MIC:15 and MIC:40 on Cryptococcus neoformans and Aspergillus niger than standard drug Amphotericin-B(MIC:25) and (MIC:50).Other derivatives $\mathbf{4 c}$ and $\mathbf{4 d}$ showed blameless activity (MIC:30) and (MIC:25)against Aspergillus flavus than AmphotericinB. Although, the remaining compound $4 \mathbf{e}$ manifested greater inhibition(MIC:25) in Aspergillus niger than the standard (MIC:50) ${ }^{26}$.<smiles>CCOC1Oc2ccccc2-c2nn(C(=O)O[Na])cc21</smiles>

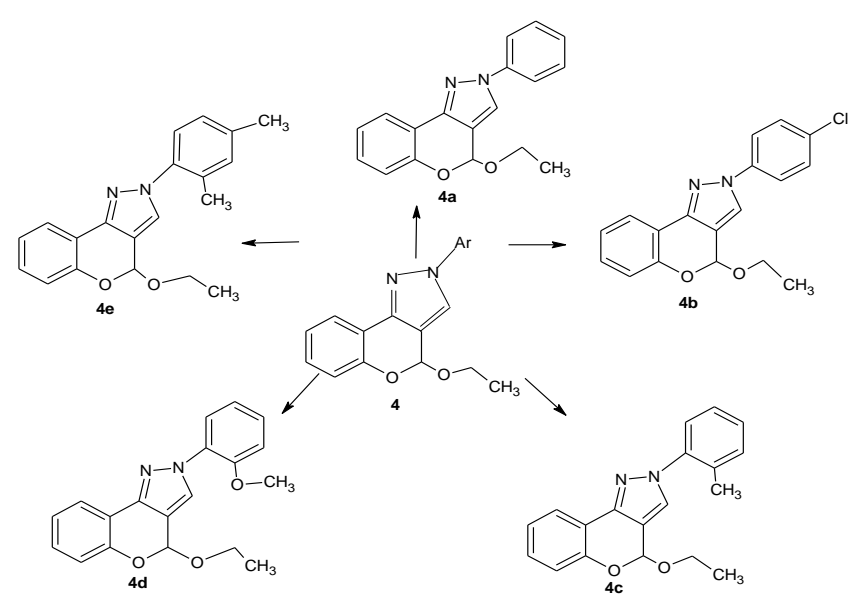

Figure 7

MF .El Shehry et al studied the synthesis, antiinflammatory, analgesic and molecular docking of a number of benzofuran derivatives combined with a series of functionalized pyrazoles. In the first step, the target compound was synthesized by cyclocondensation of 2hydroxy-4(trifluromethyl)benzaldehyde(1) with chloroacetone in acetone-alkaline medium that led to a core compound 1-[6-(trifluromethyl)benzofuran-2-yl] ethanone(2) in excellent yield. Intermediate compound(2) subjected to Clasein-Schmidt condensation with benzaldehyde or some of its substituted derivatives gave the corresponding chalcones(3a-d). Similarly, compound $\mathbf{2}$ also reacted with formyl pyrazole derivatives(4a-c) also give rise to corresponding chalcones of pyrazole(5a-c). The cyclocondensation of both chalcones ( $3 a-d)$ and (5a-c) with hydrazine hydrate upon refluxing in ethanol produced pyrazolines (6a-d) and (7a-c)(Scheme 3 ). 


\section{Scheme 3}<smiles>[R]c1ccc(C=O)c(/C=C/C(=O)C2Cc3ccc(C(F)(F)F)cc3O2)c1</smiles><smiles>[R]c1cccc(C2NN=C(c3cc4ccc(C(F)(F)F)cc4o3)C2[R]Oc2ccccc2)c1</smiles>

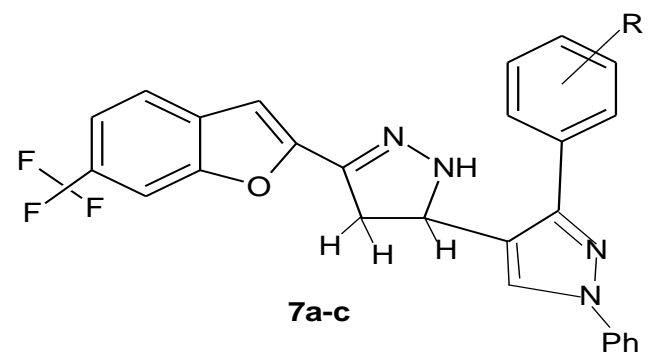

Table 1

\begin{tabular}{|l|c|}
\hline Synthesized derivatives & $\mathbf{R}$ \\
\hline $3 a-7 a$ & $\mathrm{H}$ \\
\hline $3 b-7 b$ & $4-\mathrm{Cl}$ \\
\hline $3 c-7 c$ & $4-\mathrm{CH}_{3}$ \\
\hline $3 d, 6 d$ & $4-\mathrm{NO}_{2}$ \\
\hline
\end{tabular}

The synthesized compounds were checked for their in vivo anti-inflammatory and analgesic activities in acute phase inflammation against a standard drug indomethacin. The results were expressed in mean \pm SE. Using carrageenaninduced rat paw edema bioassay, the anti-inflammatory action of synthesized compounds were evaluated. Also, the difference between treated groups and vehicle control groups was emerged using one way ANOVA followed by least significant difference. As per the obtained data, the compound 3-(1-Phenyl-3-p-tolyl-1H-pyrazol-4-yl)-1-[6-(trisfluoromethyl)benzofuran-2-yl]prop-2-en-1-one (5c) was determined to be the most potent anti-inflammatory derivative (42.3 \pm 7.4 in $4 \mathrm{hrs}$ ) with the inhibitory effect close to that of standard drug.

The synthesized compounds were also assessed for their analgesic activities using hot plate test method in comparison with indomethacin as the reference drug. Most of the synthesized compounds established some analgesic activity and among them the compound 3-[3-(4Chlorophenyl)-1-phenyl-1H-pyrazol-4-yl]-1-[6- (trifluoromethyl)benzofuran-2-yl]prop-2-en-1-one(5b) (18.20 \pm 0.73 in $2 \mathrm{hrs}$ ) was determined to be the most potent one compared to that of standard drug.

Autodock 4.2 were applied in order to explain the antimicrobial features of drug and support the experimental products. According to HB plot computation, a strong interaction with all protein receptors with comparable results was exemplified. Molecular docking modelling revealed good match with the gathered experimental data for anti-inflammatory activity of compounds $3 c, 5 a, 6 b$ and $7 b^{27}$.<smiles>O=C(/C=C/c1cn(-c2ccccc2)nc1-c1ccc(Cl)cc1)c1cc2ccc(C(F)(F)F)cc2o1</smiles>

3-[3-(4-Chlorophenyl)-1-phenyl-1H-pyrazol-4-yl]1-[6(trifluoromethyl)benzofuran-2-yl]prop-2-en-1-one(5b) 
<smiles>Cc1ccc(-c2nn(-c3ccccc3)cc2/C=C/C(=O)c2cc3ccc(C(F)(F)F)cc3o2)cc1</smiles>

3-(1-Phenyl-3-p-tolyl-1H-pyrazol-4-yl)-1-[6-(tris-fluoro methyl)benzofuran-2-yl]prop-2-en-1-one(5c)

\section{Figure 8}

B.P Bandgar et al synthesized novel series of pyrazole chalcones and studied their in vitro biological activity. The synthesis proceeds by the Clasein schmidt condensation of 1-(2,4-dimethoxy-phenyl)-ethanone(1) and substituted 1,3-
diphenyl-1H-pyrazole-4-carbaldehyde(2) resulted in formation of 1-(2,4-dimethoxy-phenyl)-3-(1,3-diphenyl-1Hpyrazol-4-yl)-propenone(3a-j). Substituted pyrazole-4carbaldehyde were prepared by Vilsmeir-Haack reaction on acetophenone phenyl hydrazones (Scheme 4).

Novel series of 10 synthesized pyrazole chalcones were screened for evaluating its anti-inflammatory (TNF- $\alpha$ and IL6 inhibitory assays), antioxidant (DPPH free radical scavenging assay) and antimicrobial activities(Agar diffusion method)against some pathogenic bacteria and fungi.

Out of 10 compounds screened (3a-j), compounds $\mathbf{3 a , 3 c}$ and $\mathbf{3 g}$ unveiled promising IL-6 inhibitory (up to $35-70 \%$ inhibition at $10 \mu \mathrm{m}$ concentration against standard drug doxamethacin, free radical scavenging (25-30\% DPPH activity, standard drug BHA) and antimicrobial activities (MIC:100 $\mu \mathrm{g} / \mathrm{mL}$ and $250 \mu \mathrm{g} / \mathrm{mL}$ ) at varied concentrations.

\section{Scheme 4}
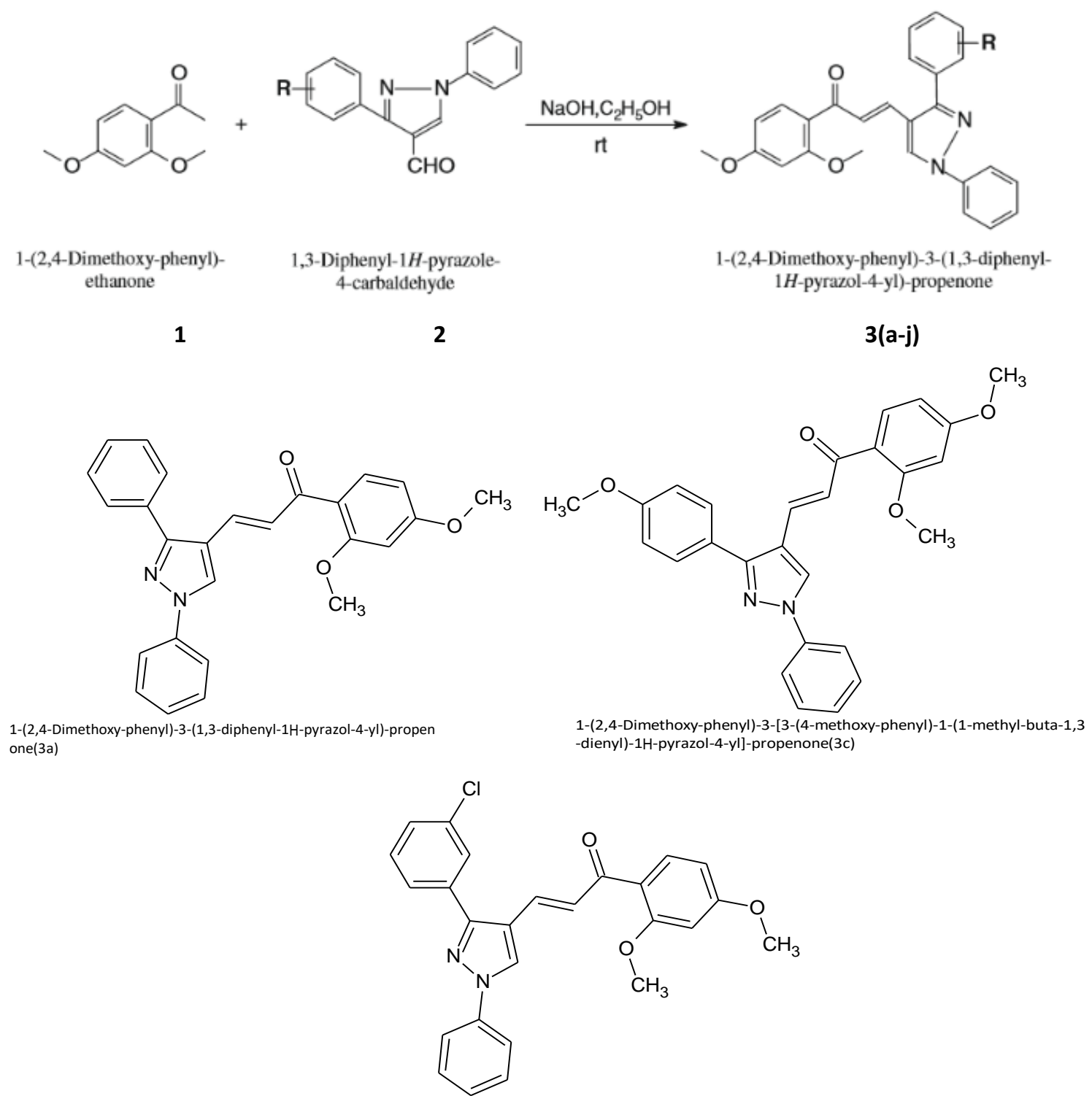

3-[3-(3-Chloro-phenyl)-1-phenyl-1H-pyrazol-4-yl]-1-(2,4-Dimethoxy-phenyl)-propeno ne(3g)

Figure 9 
For all synthesized compounds, antibiotic nystatin $(30 \mu \mathrm{g} / \mathrm{mL})$ and tetracycline $(10 \mu \mathrm{g} / \mathrm{mL})$ were used as reference antifungal and antibacterial agents respectively, for comparison. The compounds were also checked for their bioavailability by in silico study. The in silico pharmacological parameters for bioavailability such as molecular weight, $C$ log $P$ and quantum chemical descriptors such as Еномо and Ецимо of synthesized compounds were calculated by BioMed cache 6.1

From the analysis data, SAR study revealed that compounds with electron releasing groups increases the antimicrobial activity. The potency order was $\mathrm{OCH}_{3}>\mathrm{CH}_{3}>\mathrm{F}>\mathrm{Br}>\mathrm{Cl}$. Where the substituent is chlorine group, the potency order is metasortho and para. SAR and in silico drug relevant properties further confirmed that the synthesized compounds are potent lead compounds for future drug discovery studies and they revealed to be non toxic except two componds ${ }^{28}$.

Prasanna A Datar et al proposed the design of Pyrazole-3one compounds on the basis of docking studies of previously reported antidiabetic pyrazole compounds. Diabetes mellitus is a metabolic disorder that causes defect in insulin secretion, action/both. Insulin deficiency consecutively leads to chronic hypoglycaemia with troubles of carbohydrate, fat and protein metabolism.

Initially, substituted phenyl hydrazine (3)was prepared by the diazotisation reaction between substituted aniline(1), $\mathrm{NaNO}_{2}$ and $\mathrm{HCl}$ at $0-5^{\circ} \mathrm{C}$, diazonium salt(2) was produced. For the synthesis of Aryl substituted-1Hpyrazole-3-one-4-carboxylate(6), the substituted phenyl hydrazine(3) was subjected to reflux condensation in presence of Diethyl ethoxymethylene malonate (DEEM)(4) and ethanolic $\mathrm{KOH}$ (Scheme 5).

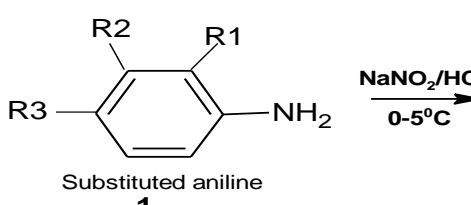
1<smiles></smiles>
2<smiles>[R3]c1ccc(NN)c([R])c1[R]</smiles>

3<smiles>CCOC(=O)C=C(C(=O)OCC)C(=O)OCC</smiles>

4<smiles>[R3]c1ccc(-n2c(=O)c(C(=O)OCC)cn2[X])c([R20])c1[R20]</smiles>

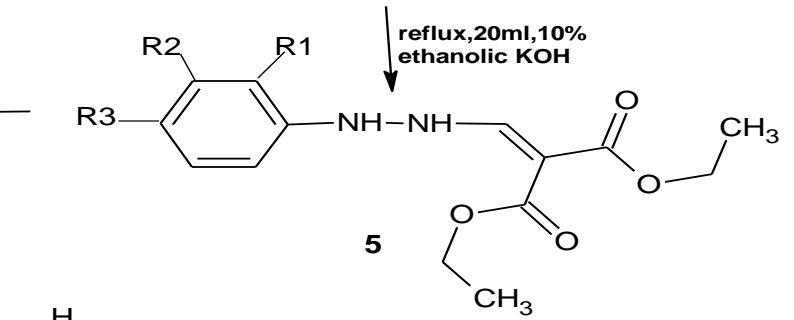<smiles>[R]Oc1nn([Tl])cc1C(=O)O</smiles><smiles>[R]n1[nH]cc(C(=O)OCC)c1=O</smiles>

Scheme 5<smiles>CCOC(=O)c1c[nH]n(-c2cccc(Cl)c2)c1=O</smiles>

ethyl-2-(3-Chlorophenyl)-3-oxo-2,3-dihydro-1 H-pyrazole-4-carb oxylate(8a)<smiles>CCOC(=O)c1c[nH]n(S(=O)(=O)c2ccc(NC(C)=O)cc2)c1=O</smiles>

ethyl-2-(4-acetamidobenzene-1-sulfonyl)-3-oxo-2,3-dihydro-1 H-p yrazole-4-carboxylate(8d)

Figure 10 
The synthesized compounds were subjected to molecular docking studies. On the basis of docking score in terms of $G$ score, the designed compounds were selectively prioritized for synthesis. The synthesized derivatives were exposed to in vivo hypoglycemic activity using alloxan induced diabetic rat and metformin as a standard. The results were computed by measuring the mean \pm SEM "p value" and analyzed by Bonfession post Hoc test, using two way ANOVA. Even though, the docking studies also helped in reducing synthetic work thereby saving time and chemical expenditure, these results tried to match with in vivo experimental study. As per the docking results, the compound ethyl-2-(3-Chlorophenyl)-3-oxo-2,3-dihydro- $1 \mathrm{H}$ pyrazole-4-carboxylate(8a) having more potency than compound ethyl 2-(4-acetamidobenzene-1-sulfonyl)-3-oxo2,3-dihydro-1 $\mathrm{H}$-pyrazole-4-carboxylate (8d) but according to in vivo experimental study, it was found that compound $\mathbf{8 d}$ has more potency over compound $\mathbf{8} \mathbf{a}$.It is due to the presence of sulphonamide moiety in compound $\mathbf{2}$ made it more potent among the series ${ }^{29}$.

Garazd et $\boldsymbol{a l}$ reported the synthesis and evaluation of anticancer activity 6-pyrazolinyl coumarin derivatives through multistep protocol. The important named reactions for the synthesis of Pyrazolinyl coumarins are Pechmann condensation, Fries rearrangement and ClaseinSchmidt condensation yielded a flavanone core. Recyclization of this flavanone core with a fivefold excess of hydrazine hydrate in EtOH upon heating produced 6-[5-aryl4,5-dihydro pyrazole-3yl ]-5-hydroxy-7-methyl coumarin (5a-q)(Scheme 6).<smiles>[R]c1c([R])c2c(OC(C)=O)cc(C)cc2oc1=O</smiles><smiles>[R]c1c([R])c2cc(OC(C)=O)ccc2oc1=O</smiles><smiles>[R7]c1ccc(C2CC(c3c(C)cc4oc(=O)c([R7])c([R])c4c3O)=NN2)cc1</smiles>

6-Pyrazolinyl coumarin derivatives(5a-q)

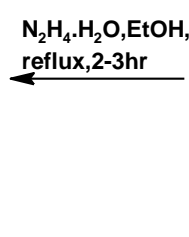<smiles>[R]c1ccccc1C1CC(=O)c2c(C)cc3oc(=O)c([R])c([R])c3c2O1</smiles>

\section{Scheme 6}

The in vitro anticancer activity of synthesized derivatives were evaluated at the concentration of $10^{-5} \mathrm{M}$ towards a panel of approximately 60 cancer cell lines. For this purpose, the synthesized derivatives were opted by National Cancer Institute $(\mathrm{NCl}$, Bethesda, USA) Developmental Therapeutic Program (DTP).As per the $\mathrm{NCl}$ protocols, the primary anticancer assays were performed. By using a protein binding dye sulforhodamine B (SRB), the end point determinations were made. The results for each compound were expressed as percent growth (GP\%) of treated cells. After the evaluation of range of percent growth, the compound 1-Hydroxy-2-[5-(4-hydroxy-3methoxyphenyl)-4,5-dihydropyrazol-3-yl]-3-methyl-

7,8,9,10-tetrahydrobenzo[c]chromen-6-one (50) was found to be more effective to against 17 cell lines with the average cell growth percent (GPmean) of 60-64\%.

Later, this compound $\mathbf{5 0}$ was chosen for an advanced assay against a panel of approximately 60 tumor cell lines. After that, this compound exhibited inhibition activity $\left(\mathrm{Gl}_{50}<10\right.$ $\mu \mathrm{M})$ against 45 of 58 human tumor cell lines with an average of $\mathrm{Gl}_{50}$ value of 10.29 . According to the SAR study, the level of antitumor activity of synthesized compounds depends on the substituents at 3,4-position of coumarin core. It is due to the presence of cyclohexyl fragment that enhanced the antiproliferative activity in comparison with cyclo pentyl residue or methyl groups. Antitumor activity assay of 17 synthesized compounds(5a-q) permitted to identify compound $50\left(\mathrm{Gl}_{50 \text { mean }}=10.20 \mu \mathrm{M}\right.$ in $\mathrm{NCl} 60$ cell line assay) along with certain sensitivity profile towards the

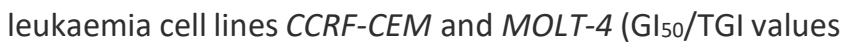
1.88/5.06 $\mu \mathrm{M}$ and 1.92/4.04 $\mu \mathrm{M}$ respectively $)^{30}$.

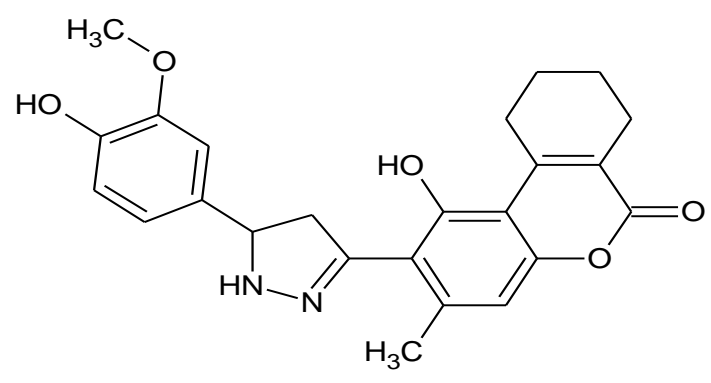

1-Hydroxy-2-[5-(4-hydroxy-3-methoxyphenyl)-4,5-dihydropyrazo -3-yl]-3-methyl-7,8,9,10-tetrahydrobenzo[c]chromen-6-one (5o)

Figure 11 
S Sidique et al explained the synthetic chemistry used for preparation of pyrazole acid scaffolds which proceeds by reaction between 1,3-diketone derivatives (2) with hydrazine hydrate via cyclocondensation and made the corresponding pyrazole ester (3). Pyrazole ester endangered to saponification provided access to pyrazole acid s(4).

For the hit optimization, this pyrazole acids was treated with HOBT,EDC and DIEA to get amides/desired hydrazide derivatives (5)(Scheme 7). Based on the initial SAR data, 2,4dichloro and 2,4-dichloro-5-fluoro substitution pattern were designated for the phenyl ring.About 26 compounds were synthesized and subjected to in vitro assay in the first library.And this led to identification of four analogues with potency values of $100 \mathrm{nM}$ or better.Insertion of hydroxy group on amide generally resulted in increased potency. While analyzing the $\mathrm{IC}_{50}$ values of pyrazole amide derivatives, it was concluded that 2,4-dichloro analogues were more potent than 2,4-dichloro-5-fluoro analogues.

Scheme 7

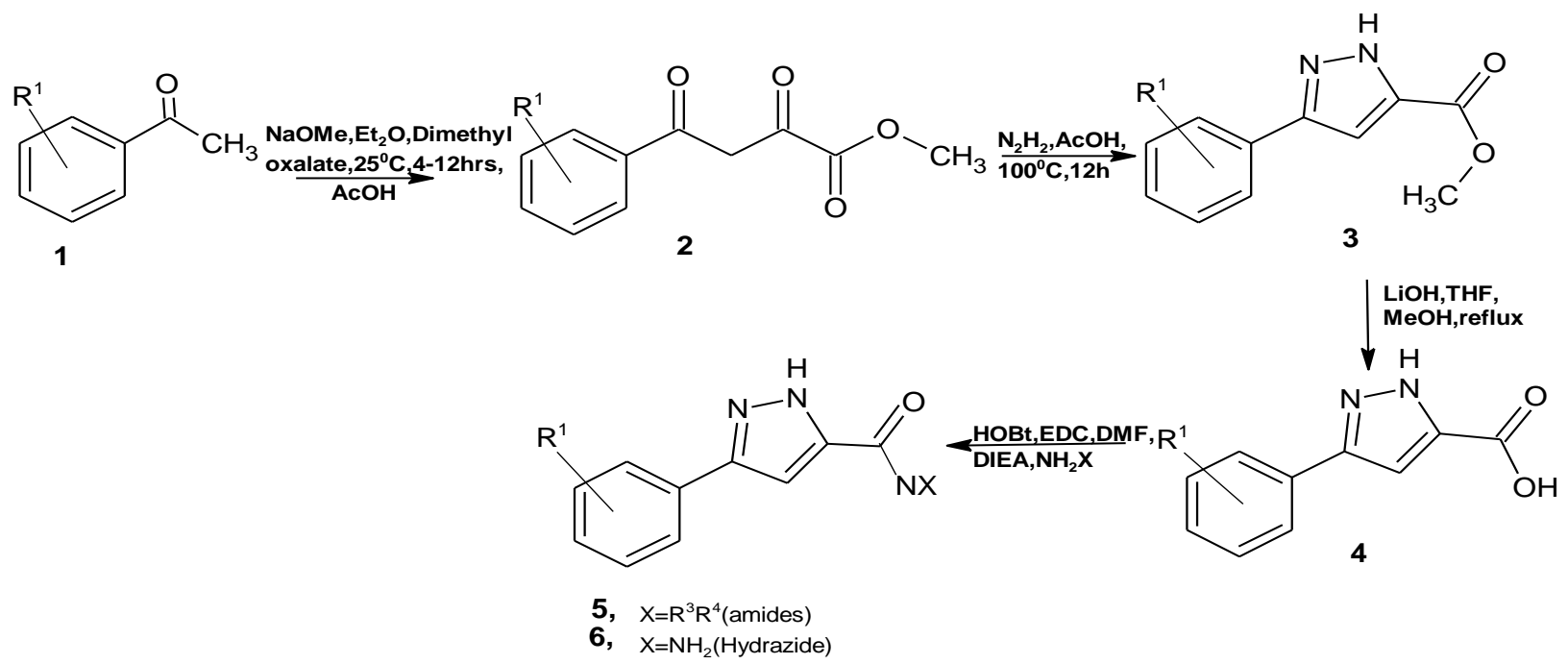

In the second library, it is found that the branching of amides generally decreases the potency, especially when the chain length was greater than 3-carbon atoms.

After analysing the data, the compound $\mathrm{N}$-(2-hydroxyethyl)3-(2,3,4-trichlorophenyl)-1H-pyrazole-5-carboxamide(5v) showed exceptional in vitro activity ie, $\mathrm{IC}_{50}$ of $0.005 \mu \mathrm{M}$ and was considered to be the most potent one. In addition to that, this compound indicated a greater selectivity for TNAP of at least 2000 fold.

In order to find out the novel TNAP inhibitors, a series of experiments were conducted with respect to its mechanism of action.The compound $\mathbf{5 v}$ obtained through hit to lead optimization was selected for additional studies and subjected to detailed kinectic studies.Subsequently, it is demonstrated that compound $\mathbf{5} \mathbf{v}$ was competitive with respect to both substrates CDP-star and DEA. It was also proved to be an extremely useful tool to facilitate research in relation to the pharmacology of TNAP. Also,compound 3 (2,4-dichlorophenyl)- $\mathrm{N}$-(2-hydroxyethyl)- $1 \mathrm{H}$-pyrazole-5carboxamide(5a) was exposed to molecular docking into the catalytic site either with serine 93 phosphorylated or with free serine 93.Due to the appearance of same binding modes, it was suggested that compound $\mathbf{5 a}$ functions as a competitive inhibitor $^{31}$.<smiles>O=C(NCCO)c1cc(-c2ccc(Cl)cc2Cl)n[nH]1</smiles>

3-(2,4-dichlorophenyl)-N-(2-hydroxyethyl)-1H-pyrazole-5-carboxamide(5a)<smiles>O=C(NCCO)c1cc(-c2cccc(Cl)c2Cl)n[nH]1</smiles>

N-(2-hydroxyethyl)-3-(2,3,4-trichlorophenyl)-1H-pyrazole-5-carboxamide(5v)

Figure 12

Beena Cheriyan et al have synthesized 1-benzoyl-3-(4methoxyphenyl)- $1 \mathrm{H}$-pyrazole-4-carbaldehydes(6) by the reaction of $\mathrm{N}^{\prime}-[(1 \mathrm{E})$-1-(4-Substituted phenyl) ethylidene) benzohydrazide(5) with Vilsmeier-Haack reagent (DMF and $\mathrm{POCl}_{3}$ ) under reflux condensation for 2 hrs (Scheme 8). All the synthesized derivatives were evaluated for their in vitro anti-inflammatory activity by using Human red blood corpuscles (HRBC) membrane stabilizing method ${ }^{32}$. 


\section{Scheme 8}<smiles>[X]c1cccc(/C(C)=N/NC(=O)c2ccccc2C(=O)N([Y])c2ccc(C(=O)NN)cc2)c1</smiles>

Among the 10 novel synthesized derivatives fitting in the series of 1-benzoyl-3-(substituted phenyl)-1H-pyrazole-4carbaldehyde,the compounds with methoxy substituted phenyl group attached to pyrazole moiety ie, 1-benzoyl-3(3methoxysubstituted phenyl)-1H-pyrazole-4-carbaldehyde (6b) exhibited comparable anti-inflammatory activity with respect to standard drug.From this work, the authors concluded that these structures can be developed as an auspicious lead for the development of new antiinflammatory agents ${ }^{33}$.<smiles>COc1cccc(-c2nn(C(=O)c3ccccc3)cc2C=O)c1</smiles>

1-benzoyl-3-(3-methoxyphenyl)-1 H-pyrazole-4-carbaldehyde(6b)

Figure 13

\section{CONCLUSION}

Pyrazoles considered as one of the imperative class of heterocyclic compounds due to their pronounced pharmaceutical and industrial importance and its structure having a 5-membered ring with three carbon atoms and two neighbour nitrogen atoms. The presence of the pyrazole nucleus in various structures leads to varied applications in different fields such as agriculture, medicine and the chemical industry. This review aims to describe the different strategies developed so far for the synthesis of various pyrazole derivatives and its diverese biological activities such as antimicrobial, anti-inflammatory, analgesic, anticancer etc. Betazole, Celecoxib, Phenylbutazone, Granisetron, Rabeprazole, Sulfinpyrazone, Aminophenazone, Antipyrine, Dichloralphenazone are some of the important marketed drugs with pyrazole nucleus.In future, the pyrazole nucleus in combination with several other heterocyclic nucleus can be expected to display synergy and pharmacological potency greater than the sum of each individual moiety's potency.

\section{REFERENCES}

1. Eicher, Hauptmann S. The Chemistry of Heterocycles. Wiley VCH; 2003.

2. Ardiansah BA. Recent reports on pyrazole-based bioactive compounds as candidate for anticancer agents. Asian J. Pharm. Clin. Res.. 2017 Jan 1;12:45.

3. Schofield K, Grimmett MR, Grimmett MR, Keene BR. Heteroaromatic nitrogen compounds: the azoles. CUP Archive; 1976 Jun 24.

4. Andes DR, Dismukes WE. Azoles. In Essentials of clinical mycology 2011 (pp. 61-93). Springer, New York, NY.

5. Sathish Kumar S, P Kavitha H. Synthesis and biological applications of triazole derivatives-a review. Mini-Reviews in Organic Chemistry. 2013 Feb 1;10(1):40-65.

6. Wei CX, Bian M, Gong GH. Tetrazolium compounds: synthesis and applications in medicine. Molecules. 2015 Apr;20(4):5528-53.

7. Bai SQ, Young DJ, Hor TA. Nitrogen-Rich Azoles as Ligand Spacers in Coordination Polymers. Chemistry-An Asian Journal. 2011 Feb 1;6(2):292-304.

8. Katritzky AR, Ramsden CA, Joule JA, Zhdankin VV. Handbook of heterocyclic chemistry. Elsevier; 2010 Aug 24.

9. Wiley RH, Behr LC. Pyrazoles, pyrazolines, pyrazolidines, indazoles and condensed rings.

10. Kumar V, Kaur K, Gupta GK, Sharma AK. Pyrazole containing natural products: synthetic preview and biological significance. European Journal of Medicinal Chemistry. 2013 Nov 1;69:735-53.

11. Walsh CT. Nature loves nitrogen heterocycles. Tetrahedron Letters. 2015 Jun 3;56(23):3075-81.

12. Vicentini CB, Mares D, Tartari A, Manfrini M, Forlani G. Synthesis of pyrazole derivatives and their evaluation as photosynthetic electron transport inhibitors. Journal of agricultural and food chemistry. 2004 Apr 7;52(7):1898-906. 
13. El-Mekabaty A. Utility of 5-amino-1-phenyl-1H-pyrazole-4carboxamide in heterocyclic synthesis. Synthetic Communications. 2014 Apr 3;44(7):875-96.

14. Kumari S, Paliwal S, Chauhan R. Synthesis of pyrazole derivatives possessing anticancer activity: current Status. synthetic communications. 2014 Jun 3;44(11):1521-78.

15. Elguero J, Katritzky AR, Denisko OV. Prototropic tautomerism of heterocycles: Heteroaromatic tautomerism-General overview and methodology. Advances in Heterocyclic Chemistry. 2000 Jan 1;76:P1-84.

16. Shaabani A, Nazeri MT, Afshari R. 5-Amino-pyrazoles: potent reagents in organic and medicinal synthesis. Molecular Diversity. 2019 Aug;23(3):751-807.

17. Abu Elmaati TM, El-Taweel FM. New trends in the chemistry of 5-aminopyrazoles. Journal of heterocyclic chemistry. 2004 Mar;41(2):109-34.

18. Alam MJ, Alam O, Alam P, Naim MJ. A review on pyrazole chemical entity and biological activity. Int. J. Pharm. Sci. Res. 2015;6:1433-42.

19. Bansal RK. Heterocyclic chemistry. New Age International; 2008.

20. Krygowski TM, Anulewicz R, Cyrański MK, Puchala A, Rasala D. Separation of the energetic and geometric contribution to the aromaticity. Part IX. Aromaticity of pyrazoles in dependence on the kind of substitution. Tetrahedron. 1998 Oct 1;54(40):12295-300.

21. Kumar RS, Arif IA, Ahamed A, Idhayadhulla A. Antiinflammatory and antimicrobial activities of novel pyrazole analogues. Saudi journal of biological sciences. 2016 Sep 1;23(5):614-20.

22. Radia S. Synthesis of some 1-aryl-3, 5-disubstitutedpyrazoles by $\mathrm{N}$-arylation of 3, 5-disubstituted-pyrazoles with 4-fluoro and 2-fluoronitrobenzene under microwave irradiation and classical heating. Arkivoc. 2006;12:138-44.

23. Katritzky AR, Scriven EF, Majumder S, Akhmedova RG, Akhmedov NG, Vakulenko AV. Direct nitration of five membered heterocycles. Arkivoc. 2005 Jan 1;3:179-91.
24. Finar IL. Organic Chemistry (Stereochemistry and Chemistry of Natural Product), 3rd reprint Pearson education (singapore) pvt. Itd. Indian branch) Delhi. 2001;2(482,828).

25. Assali M, Abualhasan M, Sawaftah H, Hawash M, Mousa A. Synthesis, biological activity, and molecular modeling studies of pyrazole and triazole derivatives as selective COX2 inhibitors. Journal of Chemistry. 2020 Mar 24;20:52-59.

26. Gurunanjappa P, Nagamallu R, Kariyappa AK. Synthesis and antimicrobial activity of novel fused pyrazoles. Int J Pharm Pharma Sci. 2015;7(2):379-81.

27. El Shehry MF, Ewies EF, Zayed EM. Synthesis of New Pyrazole Derivatives, Their Anti-Inflammatory and Analgesic Activities, and Molecular Docking Studies. Russian Journal of General Chemistry. 2019 Mar 1;89(3):18-24.

28. Bandgar BP, Gawande SS, Bodade RG, Gawande NM, Khobragade CN. Synthesis and biological evaluation of a novel series of pyrazole chalcones as anti-inflammatory, antioxidant and antimicrobial agents. Bioorganic \& medicinal chemistry. 2009 Dec 15;17(24):8168-73.

29. Datar PA, Jadhav SR. Design and synthesis of pyrazole-3-one derivatives as hypoglycaemic agents. International journal of medicinal chemistry. 2015;15:78-85.

30. Garazd Y, Garazd M, Lesyk R. Synthesis and evaluation of anticancer activity of 6-pyrazolinylcoumarin derivatives. Saudi Pharmaceutical Journal. 2017 Feb 1;25(2):214-23.

31. Sidique S, Ardecky R, Su Y, Narisawa S, Brown B, Millán JL, Sergienko $E$, Cosford ND. Design and synthesis of pyrazole derivatives as potent and selective inhibitors of tissuenonspecific alkaline phosphatase (TNAP). Bioorganic \& medicinal chemistry letters. 2009 Jan 1;19(1):222-5.

32. Parvin MS, Das N, Jahan N, Akhter MA, Nahar L, Islam ME. Evaluation of in vitro anti-inflammatory and antibacterial potential of Crescentia cujete leaves and stem bark. BMC research notes. $2015 \mathrm{Dec} ; 8(1): 1-7$.

33. Cherian B, Kumar RA, Vinod B. Pyrazole carbaldehydes as novel anti-inflammatory agents: synthesis and in vitro membrane stabilization method. Journal of Pharmaceutical Sciences and Research. 2020 Feb 1;12(2):252-7.

Source of Support: The author(s) received no financial support for the research, authorship, and/or publication of this article.

Conflict of Interest: The author(s) declared no potential conflicts of interest with respect to the research, authorship, and/or publication of this article.

For any question relates to this article, please reach us at: editor@globalresearchonline.net New manuscripts for publication can be submitted at: submit@globalresearchonline.net and submit_ijpsrr@rediffmail.com 